\title{
Acceptable applications of preimplantation genetic diagnosis (PGD) among Israeli PGD users
}

\author{
Shachar Zuckerman ${ }^{1, \star}$, David A Zeevi ${ }^{1}$, Sigal Gooldin ${ }^{2,3}$ and Gheona Altarescu ${ }^{1,3}$ \\ The use of PGD technology to select against genetic disorders and traits is increasing. Although PGD may eliminate some of the \\ obstacles related to conservative options of prenatal diagnosis, it can raise personal, social and moral questions. Ethical issues \\ concerning the justified uses of PGD are a subject of ongoing debate among medical and bioethical communities. Although \\ attitudes toward the acceptable uses of PGD were evaluated among population groups worldwide, bioethics councils were \\ criticized for ignoring public perspectives. In the last decade PGD has been widely used in Israel. The ethical guidelines were \\ created solely by medical-bioethics experts and, some felt, totally isolated from public opinions. Semi-structured in-depth \\ interviews of $\mathbf{3 7}$ users (carriers of autosomal recessive, dominant and X-linked disorders, and HLA-matching) were performed. \\ The interviews explored attitudes toward ethical and sociological aspects of PGD. The overall results of this study show highly \\ favorable attitudes of Israeli PGD users toward medical applications. Furthermore, our subjects demonstrate a more permissive \\ stand toward the controversial application of social sex selection albeit with strong objection to esthetic means of selection. PGD \\ users are coping with both genetic disease and load of the PGD procedure. Taking into consideration their opinion is important \\ since it reflects the gains and burdens of these procedures alongside the demand for future optional services. Their attitudes \\ should play an important role in the professional discussion concerning the justified uses of PGD and should significantly \\ influence the design of policy making in this field.
}

European Journal of Human Genetics (2017) 25, 1113-1117; doi:10.1038/ejhg.2017.113; published online 26 July 2017

\section{INTRODUCTION}

The introduction of new assisted reproductive technologies in the last three decades of the 20th century has created a new set of opportunities in the fields of fertility, reproduction and prenatal diagnosis.

Since the introduction of preimplantation genetic diagnosis (PGD) in $1990,{ }^{1}$ the procedure became applicable for any condition or trait with known genetic basis, including HLA matching (usually performed to select a bone marrow donor for an affected sibling) and sex selection. PGD may eliminate some of the obstacles related to conservative options of prenatal diagnosis, but can raise moral dilemmas regarding the women, the fetus and the social context.

The ethical issues and acceptable applications concerning PGD are a subject of ongoing debate among the medical, philosophical and sociological communities. Since PGD precludes termination of pregnancy (TOP), some argue that the moral justification to its use should be less strict than for routine prenatal diagnosis., ${ }^{2,3}$ Adopting this notion allows PGD application for other medical conditions in which TOP raises various ethical considerations including late onset diseases, cancer predispositions, low penetrance diseases, and HLA typing. Generally, such conditions are usually not considered justified to be tested by conservative prenatal diagnosis. ${ }^{2}$ Furthermore, the attitude toward PGD as a technology with less moral restrictions led to arguments for non medical uses, the most controversial of which is sex selection for religious and cultural reasons. ${ }^{4,5}$ The supporters of this view justify their opinion with the argument that since the procedure takes place at a very early stage of life (when the fertilized egg (morula/blastocyst) is still not considered a fetus $)^{6}$ at which point the early embryo has only limited moral value. ${ }^{7}$ In addition, in vitro fertilization usually includes selection of 'the best embryos' anyway. ${ }^{2}$ Moreover, the severity of genetic conditions can be rather subjective ${ }^{3}$ and this may influence parental autonomy regarding their decisions over future children. ${ }^{8,9}$

On the other hand, others claim that the use of PGD and its ethical and social implications resemble 'eugenic' ideas and thus advocate minimizing or even banning its practice. ${ }^{10}$ Furthermore PGD for HLA typing has produced a significant number of con arguments including the position that such procedures transform PGD children into instruments and means as opposed to ends of their own. ${ }^{11}$ Of course, there are also arguments against PGD ethics as a slippery slope which can lead to eugenics. ${ }^{12}$

This ethical complexity is demonstrated also by the way European countries are divided among those who ban PGD altogether, those who permit PGD only with strict regulation ${ }^{13}$ and those who allow it with lax regulation. The growing list of ethical committees, ${ }^{14-19}$ which discuss ethical issues concerning PGD is also prime evidence for ethical complexity of the field. Yet, for all the guidelines and medical-bioethics debates regarding PGD, these institutions were criticized for having focused authority in the hands of experts and bioethics councils while ignoring public perspectives. ${ }^{20}$

Although extensive research was performed regarding lay people's ethical evaluations for new genetic and reproductive technologies ${ }^{21-25}$ only a paucity of works on PGD users and their moral attitudes for justified applications of this technology were published. ${ }^{26-28}$ Karatas

\footnotetext{
${ }^{1}$ Medical Genetics Institute - Shaare Zedek Medical Center, Hebrew University Hadassah Medical School, Jerusalem, Israel; ${ }^{2}$ The Department of Sociology and Anthropology, Hebrew University, Jerusalem, Israel

*Correspondence: S Zuckerman, Medical Genetics Institute, Shaare Zedek Medical Center, Hebrew University, Hadassah Medical School, Bayth Str 12, Jerusalem 9103102, Israel. Tel: +972 6666336; FAX: +972 26666935; E-mail: shacharz@ekmd.huji.ac.il

${ }^{3}$ These authors contributed equally to this work.

Received 13 October 2016; revised 8 June 2017; accepted 20 June 2017; published online 26 July 2017
} 
Table 1 Characteristics of participants at the time of the interview

\begin{tabular}{|c|c|}
\hline Characteristic & Participants $(n=37) n(\%)$ \\
\hline \multicolumn{2}{|l|}{ Sex } \\
\hline Female & $24(65)$ \\
\hline Male & $13(35)$ \\
\hline \multicolumn{2}{|l|}{ Age } \\
\hline $20-30$ & 7 (19) \\
\hline $31-40$ & $25(67)$ \\
\hline $41-50$ & $4(11)$ \\
\hline$>50$ & $1(3)$ \\
\hline \multicolumn{2}{|l|}{ Origin } \\
\hline Jewish & $32(86)$ \\
\hline Muslim & $2(5)$ \\
\hline Christian & $2(5)$ \\
\hline Bedouin & $1(3)$ \\
\hline Religiosity (Jewish only) & 32 \\
\hline Secular & $13(41)$ \\
\hline Traditional & $1(3)$ \\
\hline Religious or Orthodox & $13(41)$ \\
\hline Ultra-Orthodox & $5(16)$ \\
\hline \multicolumn{2}{|l|}{ Education } \\
\hline High School & $14(38)$ \\
\hline University graduate & $23(62)$ \\
\hline \multicolumn{2}{|l|}{ Infertility problem } \\
\hline Yes & $10(27)$ \\
\hline No & $27(73)$ \\
\hline
\end{tabular}

et al. (2010) reviewed all 19 studies regarding psychological and psychosocial impact of undergoing PGD and concluded that more research is needed to collect rich data of thoughts, feelings and attitudes of PGD users, especially via in-depth interviews. ${ }^{29}$ Moreover, Cunningham et al. (2015) who reviewed nine studies regarding the experiences and attitudes to PGD in prospective parents found very little data concerning ethical dilemmas of PGD users and mentioned that parents' experiences with the use of PGD should also be considered to ensure a fully informed discussion of ethical aspects of this technology. ${ }^{30}$

The aims of this study were to expand data regarding PGD users' attitudes toward the moral aspects of various PGD applications, while also filling in existing gaps in our knowledge of PGD practice from the consumer point of view. Moreover, we also present an in-depth interpretation of PGD in specific cultural and ethnic contexts. Of particular relevance was the practical application of perceptions and standards regarding PGD technology within the realm of medical-fertility services in Israel.

\section{MATERIALS AND METHODS}

Women and men referred to the PGD unit in Shaare Zedek Medical Center, for medical reasons only, who performed PGD for at least one cycle (successive or not) were recruited for this study. A genetic counselor from the Genetic Institute in Shaare Zedek enrolled couples into the study by telephone.

Semi structured in-depth face-to face interviews (that lasted on average $45 \mathrm{~min}$ ) were carried out between February 2011 and May 2013 either at the participants' homes, a location of their choosing, or the hospital. The interviews were conducted separately with the women and men in order to protect interviewee's privacy, avoid influence of one dominant spouse, and allow for open discussion of sensitive issues.

Interviews gathered information regarding socio-demographic data and details concerning the genetic status of family members followed by reproductive history. Opened questions were asked regarding the experience of the PGD procedure and attitudes concerning moral and ethical issues. During interviews, several case studies were introduced to participants regarding different applications of PGD and its justified use. Discussion concerning their attitudes took place.

Most interviews were audio taped with the consent of the participants. For the few participants who did not agree to be audio taped, written recordings were taken during the interview. All interviews were transcribed verbatim and analyzed by the grounded theory approach. ${ }^{31,32}$ The study was approved by the institutional review boards at Shaare Zedek Medical Center.

\section{RESULTS}

Of the 34 invited couples, 24 were willing to participate. The overall response rate was $70.5 \%$. Among the couples who participated, 37 subjects were interviewed. All women (24) and 13 out of 24 spouses agreed to participate. Information about the background characteristics of subjects is summarized in Table 1.

\section{Reasons for using PGD}

Fourteen subjects (38\%) were carriers of autosomal recessive diseases, $13(35 \%)$ had an autosomal dominant condition (women or their spouses), 8 (22\%) subjects were carriers of X linked disorders (women or their spouses) and $2(5 \%)$ subjects were parents to a child that needed HLA matching.

Description of the conditions PGD was performed for is detailed in Table 2.

Two of three prominent themes discussed in the interviews developed from scenarios' that were presented to participants by the interviewer. Another theme was mentioned voluntarily by many subjects themselves without encouragement by the interviewer. Table 3 summarizes the participants' opinions towards each PGD application.

Scenarios introduced to subject regarding different applications of PGD

1. Should PGD be offered for any medical condition?. There was a high overall approval of PGD usage for any medical condition among the 37 subjects. Thirty three subjects (89\%) agreed that PGD should be performed for any medical condition, even non-lethal conditions, treatable conditions (eg, deafness) and late-onset conditions (eg, cancer predisposition). These findings were applicable both for subjects who performed PGD for severe life-shortening conditions (eg, Tay-Sachs) and for subjects performing PGD for non-lethal treatable conditions (eg, non syndromic deafness). Three subjects (8\%) were undecided regarding PGD for less severe conditions and only one subject $(3 \%)$ did not approve of PGD for less severe conditions, ie, deafness.

The main argument in favor of selecting an unaffected embryo was preventing a life of suffering from a future child who can be assured of a 'good' and 'normal' life. When discussing the option of PGD for mild conditions subjects declared that they would do it in order to prevent their offspring from any deviation from norm.

'I think a deaf child can live a fulfilling and happy life but if I can prevent him from being born deaf- why not? If I could prevent giving birth to a deaf child I would prefer it'

(36 year old woman, carrier of Fragile X syndrome) 
Table 2 Referrals for PGD by inheritance patterns

\begin{tabular}{|c|c|c|c|}
\hline \multicolumn{3}{|l|}{ Referrals for $P G D$} & Couples $n=24$ \\
\hline \multicolumn{4}{|l|}{ Autosomal Dominant Conditions } \\
\hline \multicolumn{2}{|l|}{ Myotonic Dystrophy type 1} & & 3 \\
\hline \multicolumn{2}{|l|}{ Neuro-fibromatosis type 1} & & $2^{\mathrm{a}}$ \\
\hline \multicolumn{2}{|l|}{ Autosomal Dominant Polycystic Kidney } & & 1 \\
\hline \multicolumn{2}{|l|}{ Pseudohypoparathyroidism } & & 1 \\
\hline \multicolumn{2}{|l|}{ BRCA1 } & & 1 \\
\hline \multicolumn{2}{|c|}{ Multiple Endocrine Neoplasia type 2 (MEN2) } & & 1 \\
\hline \multicolumn{4}{|l|}{ Autosomal Recessive Conditions } \\
\hline \multicolumn{2}{|l|}{ Connexin 26 (Non Syndromic Deafness) } & & 2 \\
\hline \multicolumn{2}{|l|}{ Cystic Fibrosis } & & 2 \\
\hline \multicolumn{2}{|c|}{ Severe combined immunodeficiency (SCID) } & & 1 \\
\hline \multicolumn{2}{|l|}{ Familial Dysautonomia } & & 1 \\
\hline \multicolumn{2}{|l|}{ Leukodystrophy } & & 1 \\
\hline \multicolumn{2}{|l|}{ Tay Sachs+Gaucher } & & $1^{\mathrm{b}}$ \\
\hline \multicolumn{2}{|l|}{ Krabe+ Pompe } & & $1^{\mathrm{b}}$ \\
\hline \multicolumn{4}{|l|}{$X$ linked Conditions } \\
\hline \multicolumn{2}{|l|}{ Fragile $X$} & & 2 \\
\hline \multicolumn{2}{|l|}{ Incontinentia Pigmenti } & & 1 \\
\hline \multicolumn{2}{|l|}{$\mathrm{X}$ linked Ichthiosis } & & 1 \\
\hline \multicolumn{3}{|l|}{ HLA Matching (Human leucocyte antigen) } & 2 \\
\hline \multicolumn{4}{|c|}{$\begin{array}{l}\text { an one couple both partners were diagnosed with Neuro-fibromatosis type } 1 . \\
\text { bBoth partners were double heterozygotes. }\end{array}$} \\
\hline \multicolumn{4}{|c|}{ Table 3 Participants' opinions towards PGD different applications } \\
\hline Reason for $P G D$ & Agree $n(\%)$ & Indecisive $n(\%)$ & Disagree $n(\%)$ \\
\hline $\begin{array}{l}\text { Any medical condition } \\
\text { Social sex selection-general population }\end{array}$ & $\begin{array}{l}33(89) \\
21(57)\end{array}$ & $\begin{array}{l}3(8) \\
3(8)\end{array}$ & $\begin{array}{c}1(3) \\
13(35)\end{array}$ \\
\hline $\begin{array}{l}\text { Social sex selection-self use } \\
\text { Esthetic traits }\end{array}$ & $9(24)$ & $2(6)$ & $\begin{array}{l}26(70) \\
10(27)^{\mathrm{a}}\end{array}$ \\
\hline
\end{tabular}

aAll subjects actively mentioned this application, expressed strong objection towards it.

The condition's age of onset did not affect arguments for preventing any kind of abnormality.

'I would intervene only on the medical level. If you can prevent an unpleasant life from coming into fruition, at any stage of life... definitely, even diseases of older age, it [the birth of an affected child] just seems for me unnecessary, simply unnecessary, for what?'

(50 year old man with Autosomal dominant polycystic kidney disease $(\mathrm{ADPK}))$

2. Should PGD be used for social sex selection?. On this subject, our Israeli sample showed permissive tendency as with the previous question. The majority of surveyed subjects $(21 ; 57 \%)$ thought it would be appropriate to allow social sex selection for family balancing or because of cultural preferences. Yet, most of those in favor of sex selection thought performing PGD for this use is an extreme step.

'I can't get into peoples' opinions... if they agree to get through this uneasy process, so probably it is very important to them'

(35 years old women, carrier of MEN2)
Some others were much more enthusiastic about it, especially when the subject had personal relevance.

II think it is great for many people that... for example my brother who has three boys and they wish for a girl...I think after two children of the same sex it would be right to give the choice. I don't see why not, it's not like it is immoral... and the state should $100 \%$ finance it'

(42 year old man, his spouse is a carrier of X linked Ichthiosis)

Nevertheless, 13 subjects (35\%) disapproved of this use; some of whom expressed strong objections and regarded it as immoral.

'Boy or girl is a very big moral question. I don't think the state should allow it. It's like abortions in china...I think it brings us back to dark ages allowing people to select the sex of the baby based on caprices and cultural stands. It's very problematic'

(36 year old woman, carrier of Fragile X)

Three other subjects (8\%) were indecisive regarding PGD for social sex selection in the general population.

When subjects were asked about the prospective personal use of sex selection during PGD cycles, the majority (26; 70\%) would not consider testing the future sex of the fetus, two subjects $(6 \%)$ were undecided, and 24\% (nine subjects) said they would use it.

The main reason for demanding sex selection was family balancing.

'If someone has 3 or 4 boys, should he do PGD (for sex selection)? Definitely! Definitely! Listen it's an emotional need... Even if I didn't need PGD anyway, I would do it. I would never give up having girls!'

(39 year old woman, carrier of X linked Ichthiosis)

3. Should PGD be used for esthetic traits?. The case reports presented to subjects were applications clinically available via PGD at the time of study, and not theoretical applications which might be practically accessible in the future, e.g. intelligence level, sexual orientation and esthetic traits. However, although not presented with such a case, about a third of subjects raised the theoretical possibility of embryo selection based on esthetic traits. Lack of tolerance regarding this use was prominent among all ten subjects who actively mentioned it on their own. Most subjects regard the traits of blue eyes and blonde hair as examples of PGD use which are totally unjustified.

'(I am not in favor of) all the radical things healthy people perform PGD for: a child 1.80 meters, blue eyes, blonde hair, resembling Michael Phelps...I would not resort to IVF to choose Alpha kids'

(31 year old woman with NF1 syndrome)

'It is not that I want a blonde child with blue eyes. I am also bold. The level of genetic engineering is not legitimate in order to keep only the perfect child'

(37 year old man, his spouse is a carrier of Fragile $\mathrm{X}$ )

Arguments of subjects in favor of different applications of PGD Justifications for PGD usage in various case reports were based on several arguments:

\section{The early stage of embryo manipulation}

'It's not that we are doing...it's not that we are sorting healthy, happy, chubby fetuses with fingers and we tell them 'OK, you are not fine', it's not like stories in China where they give birth to baby girls and throw 
them out somewhere. It's really not... if people really want to do it so let them, definitely, I think there is no dealing with lives when it's on the level of eight cells. This is what I think'

- (30 year old man, carrier of non-syndromic deafness)

'I don't think there is life in the early stages after fertilization, so there is also no death(the systems are not developed yet); therefore I feel much more comfortable with the PGD process that is taking place at a very very early developmental stage,

(50 year old man with autosomal dominant polycystic kidney (ADPK))

2. PGD process produces embryos that are solely from the genetic material of the parents without any genetic manipulation.

'I don't see PGD as a problematic intervention. You can choose from a number of prenatal options which were 'created' by both members of a couple; so as long as you don't add any extra factor ... then it's OK'

(36 year old man, carrier of cystic fibrosis)

3. Parent autonomy. The most common argument in favor of PGD for any reason was the autonomy parents should have regarding decisions pertaining to their future offspring.

'I don't want to choose (the sex of the fetus) as long as he is healthy we don't care if it's a boy or a girl (but regarding this application) I think a person should decide on his own'

( 35 year old man, his spouse is a carrier of Fragile X)

'We can't judge people who do (sex selection)For me it is more important he will not have Myotonic dystrophy. (for others) It should definitely not be forbidden'.

(26 year old women, her spouse is a carrier of myotonic dystrophy)

\section{DISCUSSION}

The aim of this study was to explore the ethical attitudes and concerns of a population most influenced by the new technology of PGD, the users themselves.

Our subjects divide the uses of PGD from the most justified uses to the most unjustified. On one side of spectrum, the justified application side, lie all medical uses of PGD, both severe and mild. In this regard our subjects accept the medical model, defined by the ESHRE task force on ethics and law, 'PGD as a means to avoid the transmission of disease'. ${ }^{33}$ Compared with other studies, our sample of PGD users show a similarly high general acceptance of PGD for less severe conditions as in an Australian study. ${ }^{26}$ Our cohort is much more permissive than PGD users in the UK who express stark contrast between embryo selection for individuals that would not develop severe life threatening genetic disease and embryo selection for other trivial applications. ${ }^{27}$ This liberal/permissive attitude within our study sample is consistent with contemporary norms in Israeli society which have the highest rates of assisted reproductive technology in the world ${ }^{34}$ yet also has strong tendency to 'quest for the perfect baby' 35,36 and prevent the birth of disabled fetuses. ${ }^{37}$

In the middle of the spectrum lies the use of social sex selection which was justified by some PGD users and considered unacceptable by others. The moral rationale of those in favor of this use was parental autonomy to choose what they wish for their child. Those against social sex selection used universal moral codes including social responsibility and theological reasoning.
The question regarding PGD for social sex selection was investigated in this study, since it is one of the most controversial questions regarding PGD usage in the literature and in Israeli public debate. ${ }^{8,38}$ The option for sex selection is highly regulated by Israeli law. ${ }^{39}$ On one hand, there is high theoretical approval of PGD for social sex selection by the PGD consumers, as observed in this study. On the other hand, we have also observed low demand for using PGD for personal non-medical reasons. Interestingly, previous studies involving Middle East populations have addressed social sex selection from the religious Muslim perspective, where there is a strong favoritism for male sex. ${ }^{5,40}$ This notion is also discussed in relation to Jewish perspectives. ${ }^{4}$ Yet others strictly condemn this PGD non-medical application using religious ${ }^{41}$ or social arguments. ${ }^{38}$

On the other side of the spectrum, we found a strong opposition in our study cohort towards the PGD selection of fetuses based on esthetic traits. Lack of tolerance for this course of action was vehement among the subjects who brought it up. They saw no connection whatsoever between their own perceived justified PGD application (which was to select against a medical condition) and what they considered to be unacceptable esthetic trait selection. The moral rationale for this attitude included mostly objections to human intervention with the natural diversity of human kind. It was important for PGD users to declare that their use of PGD for medical intervention was not 'immoral' to the extent of choosing a blonde hair and blue eyed child. Similarly, this strong objection to selection of embryos on the basis of esthetic traits is common to other groups of PGD users. This issue was well analyzed in Roberts and Franklin ${ }^{27}$ ethnographic research of PGD users who established clear distinctions between choosing sex or trivial physical characteristics vs selecting embryos that would not develop genetic disease. This distinction between health related appropriation of PGD and inappropriate esthetic related PGD application was reinforced by subjects felt highly compelled to justify the morality of their action for their children. This need for self encouragement reveals some of the subconscious dilemmas that PGD subjects still experience when considering their own use of new reproduction technology.

Our study shows that subjects think that parents' autonomy regarding their future offspring is the strongest argument for the question of who should decide whether PGD use is appropriate. This notion is prominent also in other studies of PGD users ${ }^{26}$ and ethicists, ${ }^{9}$ although other users accept the primary position of ethical committees worldwide which stress the need for regulating the different PGD applications. ${ }^{27}$

The difference between hypothetical and actual intent is an acknowledged limitation in studies regarding use of assisted reproductive technology and specifically PGD. ${ }^{42}$ Therefore, one of our study's main strengths is overcoming this methodological gap by addressing diverse cohort of PGD users who are either actively involved in the process or intend to start another cycle in the near future.

The limitations of our study were first that the opinions presented are coming from a selected group in a specific context and thus do not necessarily represent the opinion of the general population nor that of PGD users in other settings and locales. Certainly, one must take into account the effect of local government regulations, health system and moral attitude in other geographic locations before deciding on public regulations regarding PGD. Second, there might be a biased ascertainment in the current study towards those who are more in favor of PGD being more inclined to accept interview requests for PGD-related matters. Moreover, the majority of our samples were of white Jewish ethnicity, with few Muslim and Bedouin subjects. 
Although this sample still represents the typical gamut of PGD users in Israel, it would probably be more informative to explore these issues with a more ethnically diverse sample in the future. Furthermore, exploring these opinions in other groups, for example couples who have chosen not to perform PGD or couples in the general public, should also be considered when creating guidelines.

In conclusion, the attitudes and opinions that are reflected in this article seem predictive of new realities given that PGD technology is rapidly becoming more and more accessible to the general public. Accordingly, it is very important for the research community to explore and then assimilate these sentiments while approaching the design of moral and ethic regulation of PGD application going forward.

\section{CONFLICT OF INTEREST}

The authors declare no conflict of interest.

\section{ACKNOWLEDGEMENTS}

This study was supported in part by the 'Israel National Institute for Health Policy Research' (grant no. M/26/2010, to S.Z.). We thank the participating PGD users for taking part in the study and sharing their attitudes.

1 Handyside AH, Kontogianni EH, Hardy K, Winston RM: Pregnancies from biopsied human preimplantation embryos sexed by Y-specific DNA amplification. Nature 1990; 344: 768-770.

2 Kuliev A, Verlinsky Y: Place of preimplantation diagnosis in genetic practice. Am J Med Genetics Part A 2005; 134A: 105-110.

3 Krahn T: Preimplantation genetic diagnosis: does age of onset matter (anymore)? Med Health Care Philos 2009; 12: 187-202.

4 Grazi RV, Wolowelsky JB, Krieger DJ: Sex selection by preimplantation genetic diagnosis (PGD) for nonmedical reasons in contemporary Israeli regulations. Camb $Q$ Healthc Ethics: CQ: Int J Healthc Ethics Comm 2008; 17: 293-299.

5 Serour GI: Islamic perspectives in human reproduction. Reprod Biomed 2008; 17 (Suppl 3): 34-38.

6 Cameron C, Williamson R: Is there an ethical difference between preimplantation genetic diagnosis and abortion? J Med Ethics 2003; 29: 90-92.

7 de Wert G, Liebaers I, Van de Velde H: The future (r)evolution of preimplantation genetic diagnosis/human leukocyte antigen testing: ethical reflections. Stem Cells 2007; 25: 2167-2172.

8 Heyd D: Male or female, we will create them: the ethics of sex selection for non-medical reasons. Ethical Perspect/Catholic University of Leuven European Centre for Christian Ethics 2003; 10: 204-214.

9 Savulescu J: Procreative beneficence: why we should select the best children. Bioethics 2001; 15: 413-426.

10 Stock G: Germinal choice technology and the human future. Reprod Biomed 2005; 10 (Suppl 1): S27-S35.

11 Edwards RG: Ethics of PGD: thoughts on the consequences of typing HLA in embryos. Reprod Biomed 2004; 9: 222-224.

12 Ricci ML: Assisted procreation and its relationship to genetics and eugenics. Hum Reprod Genet ethics 2009; 15: 7-27.

13 Basille C, Frydman R, El Aly A et al: Preimplantation genetic diagnosis: state of the art. Eur J Obstet Gynecol Reprod Biol 2009; 145: 9-13.

14 Protection GFMoJaC. German Embryo Protection Act. Embryonenschutzgesetz vom 13 Dezember 1990 (BGBI I S 2746) 13.12.1990.

15 Authority UHFaE: Code of Practice: Embryo testing and sex selection. http://wwwhfeagovuk/, 2016.

16 Europe Co: Steering Committee on Bioethics. http://wwwcoeint/, 2004
17 Bioethics TPsCo, Washington DC. Reproduction and Responsibility: The Regulation of New Biotechnologies. https://bioethicsarchivegeorgetownedu, 2004.

18 Ethics ETFo, Law i, Pennings G et al: ESHRE Task Force on Ethics and Law 13: the welfare of the child in medically assisted reproduction. Hum Reprod 2007; 22 2585-2588.

19 M R: Bioethics issues in PGD (Hebrew). the National Bioethics Council: Israel, 2008.

20 Jones DG, King MR, Whitaker MI: Who gets born? How did New Zealand's Bioethics Council arrive at its recommendations? N Z Med J 2009; 122: 84-91.

21 Borkenhagen A, Brahler E, Wisch S, Stobel-Richter Y, Strauss B, Kentenich $H$ : Attitudes of German infertile couples towards preimplantation genetic diagnosis for different uses: a comparison to international studies. Hum Reprod 2007; 22: 2051-2057.

22 Hui PW, Lam YH, Chen M et al: Attitude of at-risk subjects towards preimplantation genetic diagnosis of alpha- and beta-thalassaemias in Hong Kong. Prenat Diagn 2002; 22: $508-511$.

23 Jae GA, Lewkowitz AK, Yang JC, Shen L, Rahman A, Del Toro G: Barriers to conceiving sibling donors for sickle cell disease: perspectives from patients and parents. Ethnicity Health 2011; 16: 431-445.

24 Quinn G, Vadaparampil S, Wilson C et al: Attitudes of high-risk women toward preimplantation genetic diagnosis. Fertil Steril 2009; 91: 2361-2368.

25 Winkelman WD, Missmer SA, Myers D, Ginsburg ES: Public perspectives on the use of preimplantation genetic diagnosis. J Assisted Reprod Genet 2015; 32: 665-675.

26 Katz MG, Fitzgerald L, Bankier A, Savulescu J, Cram DS: Issues and concerns of couples presenting for preimplantation genetic diagnosis (PGD). Prenatal Diagnosis 2002; 22: 1117-1122.

27 Roberts C, Franklin S: Experiencing new forms of genetic choice: findings from an ethnographic study of preimplantation genetic diagnosis. Hum Fertility 2004; 7 . 285-293.

28 van Rij MC, Gielen M, Lulofs R et al: Profiles and motives for PGD: a prospective cohort study of couples referred for PGD in the Netherlands. Hum Reprod 2011; 26: $1826-1835$.

29 Karatas JC, Strong KA, Barlow-Stewart K, McMahon C, Meiser B, Roberts C: Psychological impact of preimplantation genetic diagnosis: a review of the literature. Reprod Biomed 2010; 20: 83-91.

30 Cunningham J, Goldsmith L, Skirton $\mathrm{H}$ : The evidence base regarding the experiences of and attitudes to preimplantation genetic diagnosis in prospective parents. Midwifery 2015. 31: 288-296.

31 Charmaz K: Constructing Grounded Theory: A Practical Guide through Qualitative Analysis (Introducing Qualitative Methods Series). SAGE Publications: London, 2006.

32 Shkedi AWords of meaning: qualitative research-theory and practice (Hebrew)Tel-Aviv university Ramot: Tel-Aviv, 2003.

33 De Wert G, Dondorp W, Shenfield F et al: ESHRE task force on ethics and Law22: preimplantation genetic diagnosis. Hum Reprod 2014; 29: 1610-1617.

34 Shalev C, Gooldin S: The uses and misuses of in vitro fertilization in Israel: some sociological and ethical considerations. Nashim: J Jewish Women's Studies \& Gender Issues 2006; 151-176.

35 Remennick L: The quest for the perfect baby: why do Israeli women seek prenatal genetic testing? Sociol Health IIIness 2006; 28: 21-53.

36 Hashiloni-Dolev Y: Between mothers, fetuses and society: Reproductive genetics in the Israeli-Jewish context. Nashim. J Jewish Women's Stud Gender Issues 2006; 12 129-150

37 Raz A: 'Important to test, important to support' attitudes toward disability rights and prenatal diagnosis among leaders of support groups for genetic disorders in Israel. Soc Sci Med 2004; 59: 1857-1866.

38 Landau R: Sex selection for social purposes in Israel: quest for the 'perfect child' of a particular gender or centuries old prejudice against women? J Med Ethics 2008; 34 e10.

39 Health IMo: National Committee for sex selection by PGD. instruction no 7/12 2012. http://www.health.gov.il/.

40 Eftekhaari TE, Nejatizadeh AA, Rajaei $\mathrm{M}$ et al: Ethical considerations in sex selection. J Educ Health Promot 2015; 4: 32.

41 Popovsky $M$ : Jewish perspectives on the use of preimplantation genetic diagnosis. J Law Med Ethics: J Am Soc Law Med Ethics 2007; 35: 699-711, 513.

42 Ormondroyd E, Donnelly L, Moynihan C et al: Attitudes to reproductive genetic testing in women who had a positive BRCA test before having children: a qualitative analysis. Eur J Hum Genet 2012; 20: 4-10. 